\title{
Update on the use of trandolapril in the management of cardiovascular disorders
}

\author{
Ariel Diaz' \\ Anique Ducharme ${ }^{2}$ \\ 'University of Montreal, Trois-Rivieres; \\ ${ }^{2}$ Department of Medicine, Montreal \\ Heart Institute Research Center, \\ Montreal, Quebec, Canada
}

\begin{abstract}
Trandolapril is a well known angiotensin converting enzyme (ACE) inhibitor with many cardiovascular (CV) indications. The objectives of this article are to review the pharmacokinetics and pharmacodynamics properties of trandolapril and to focus on its clinical relevance in cardiovascular medicine. Various populations have been studied in large clinical trials including patients with congestive heart failure (CHF) after an acute myocardial infarction (AMI), diabetics, patients with hypertension (HTN), stable coronary artery disease (CAD) and prevention of proteinuria. Long-term treatment with trandolapril in patients with reduced left ventricular function soon after AMI significantly reduced the risk of overall mortality, mortality from CV causes, sudden death, and the development of severe CHF. Treatment with trandolapril after AMI complicated by left ventricular dysfunction appears to be of considerable importance in patients with diabetes mellitus by saving lives and substantially reducing the risk of progression to severe CHF as well. Moreover, trandolapril reduces progression to proteinuria in high-risk patients. Some of the advantages of trandolapril over other ACE inhibitors are the wide spectrum of patient populations studied, the well established dosage and its proven trough-to-peak effect ratios permitting a safe once-a-day administration.
\end{abstract}

Keywords: trandolapril, angiotensin converting enzyme inhibitors, hypertension cardiovascular diseases, diabetic nephropathy

\section{Introduction}

In the early 1970s, a Brazilian biologist noticed that the venom of the pit viper (Bothrops jararaca) was able to potentiate the action of bradykinin. This discovery led to the development of teprotide. This nonapeptide is a potent angiotensin converting enzyme (ACE) inhibitor and causes hypotension in vivo. Further research expanded the knowledge of ACE inhibition and led to the introduction of captopril in 1975, the first orally active ACE inhibitor (Aurell 1998; Hedner et al 1998).

Trandolapril is an orally administrated ACE inhibitor that has been used for over two decades in the management of various cardiovascular disorders. This review will briefly describe the pharmacodynamic and pharmacokinetic properties of trandolapril, then discuss in more detail its use in patients with congestive heart failure (CHF) after acute myocardial infarction (AMI), in diabetic patients, in patients with arterial hypertension (HTN) and stable coronary disease, and in the prevention of proteinuria.

\section{Pharmacodynamic and pharmacokinetic properties}

Trandolapril is a non-sulfhydryl prodrug that is rapidly hydrolyzed in the liver to the active diacid compound, trandolaprilat. Trandolaprilat has a high binding affinity for $\mathrm{ACE}$ and the drug concentration required to inhibit $\mathrm{ACE}$ activity by $50 \%\left(\mathrm{IC}_{50}\right)$ is less than that of enalaprilat, captopril and quinaprilat, and similar to that of ramiprilat (Wiseman and McTavish 1994). Maximal ACE inhibition after repeated doses occurs at 3 hours in younger patients and at 1.5 hours in older patients (Arner et al 1994). 
Trandolapril is a highly lipophilic drug, which may facilitate tissue ACE inhibition with potential effects in cardiovascular remodeling (Wiseman and McTavish 1994). The main pharmacodynamic effects of trandolapril are achieved by a reduction in plasma angiotensin-II levels. This leads to a reduction in peripheral vasoconstriction, blood pressure, total peripheral resistance, and decreased sodium and water retention by the kidney. ACE inhibitors increase bradykinins production, which explains their main side effect of dry cough (Figure 1).

Several small size non-blinded pharmacodynamic studies were done to assess cardiovascular effects of trandolapril. In one study of 27 hypertensive patients aged 18-75, plasma norepinephrine levels were either statistically unchanged or decreased $(17 \%-32 \%)$. In this trial, a single-blind, 2-week placebo run-in period was followed by 2 double-blind crossover periods, each of 4 weeks, when patients were randomized to receive either $2 \mathrm{mg}$ trandolapril once daily or matching placebo (Petrie et al 2000). In another trial of heart failure patients with NYHA class III or early class IV symptoms, neurohumoral activation was attenuated and plasma epinephrine decreased (32\%) (van der Ent et al 1998). All patients had heart failure symptoms combined with a cardiothoracic ratio $>0.50$ on chest $x$-ray and/or left ventricular (LV) ejection fraction $\leq 0.35$ and/or capillary wedge pressure $>15 \mathrm{mmHg}$, and previous treatment with ACE inhibitors was stopped for at least 1 week before (van der Ent et al 1998). Cardiac performance indices (LV stroke work and volume) were also significantly increased (van der Ent et al 1998). In other small studies, significant reductions were observed in total peripheral resistance $(13 \%-23 \%)$, LV hypertrophy and remodeling (LV mass index 24\%), end-systolic stress (8\%-12\%), pulmonary capillary wedge pressure $(43 \%-45 \%)$, and pulmonary artery pressure (29\%) (De Luca et al 1992; Guller et al 1993; van der Ent et al 1998).

The bioavailability of trandolapril is not affected by concomitant food intake. One third of the drug is excreted in the urine and the remaining two thirds in feces (Wiseman and McTavish 1994). Dosage reduction is recommended in patients with severe renal failure, since renal clearance of trandolapril is directly proportional to creatinine clearance (Danielson et al 1994). In healthy volunteers, no significant interactions were observed when trandolapril was co-administered with most frequently used cardiovascular (CV) drugs including warfarin (Wiseman and McTavish 1994; Meyer et al 1995).

\section{Therapeutic use}

\section{Patients with LV dysfunction} after myocardial infarction (MI)

The TRAndolapril Cardiac Evaluation (TRACE) study assessed the effect of ACE inhibition with trandolapril on mortality (overall and cardiovascular) and cardiovascular morbidity in patients surviving an AMI with reduced LV function (TRACE 1994). TRACE was a randomized, doubleblind, placebo-controlled study conducted in 27 centers



Figure I Renin-angiotensin-aldosterone system and site of action of different drugs that block the system as well as bradykinin by-products. Abbreviations: ACE, angiotensin-converting enzyme; $\mathrm{AT}_{1}$, angiotensin II type I; EDHF, endothelium-derived hyperpolarizing factor; SNS, sympathetic nervous system. 
in Denmark. Eligible patients had an AMI confirmed by elevated cardiac enzymes, electrocardiographic changes, and/or chest pain and reduced LV function confirmed by an echocardiography-derived wall motion score index $($ WMSI $) \leq 1.2$. A WMSI $\leq 1.2$ approximates a left ventricular ejection fraction $\leq 35 \%$ in the nine-segment model originally described by Heger et al (1980). Patients with residual ischemia and/or clinical heart failure were not excluded. Only the following exclusion criteria were used: an absolute or relative contraindication or a definite need for ACE inhibition; severe, uncontrolled diabetes mellitus; hyponatremia ( $<125 \mathrm{mmol} / \mathrm{L}$ sodium); an elevated serum creatinine level $(2.3 \mathrm{mg} / \mathrm{dL}$ [200 $\mathrm{mmol} / \mathrm{L}])$; pregnancy or lactation; acute pulmonary embolism; vascular collagen disease; non-ischemic obstructive heart disease; unstable angina requiring immediate invasive therapy; severe liver disease; neutropenia or concurrent immunosuppressive or antineoplastic therapy; drug or alcohol abuse; or treatment with another investigational drug. Trandolapril or placebo was added to conventional therapy 3 to 7 days after AMI (mean 4.5 days). Between May 1990 and June 1992, 6674 patients (7010 infarctions) were screened. A total of 2614 patients had a wall motion index $\leq 1.2$; of these, 1749 were included, with a follow-up of 24 to 50 months. Overall 1-year mortality in the study was $24 \%$ (TRACE 1994).

Baseline characteristics showed no significant differences except the use of nitrates, which was higher in the active drug group $(\mathrm{p}<0.005)$ (Kober et al 1995). Mean age was 67 years and $70 \%$ of the population were males. $47 \%$ had had an anterior Q wave MI and $21 \%$ of patients had a Killip class $\geq 2$ at randomization. The study was done in the early 1990s with 90\% receiving aspirin, 16\% $\beta$-blockers, $28 \%$ calcium channel antagonists and around 30\% digoxin or digitalis (Kober et al 1995).

During the study period, 304 patients $(34.7 \%)$ in the trandolapril group died, compared with 369 (42.3\%) in the placebo group $(\mathrm{p}=0.001)$ (Kober et al 1995) (Figure 2). The relative risk (RR) of death from any cause in the trandolapril group, compared with the placebo group, was $0.78(95 \%$ confidence interval [CI] $0.67-0.91 ; \mathrm{p}=0.001)$, mostly from cardiovascular causes (226 vs 288 in the trandolapril and placebo groups respectively, RR 0.75, 95\% CI $0.63-0.89, \mathrm{p}=0.001)$. Fewer patients died suddenly in the trandolapril vs the placebo group (105 vs 133 , RR 0.76 , $95 \%$ CI $0.59-0.98, \mathrm{p}=0.03$ ). Time to other endpoints such as reinfarction and severe heart failure are shown in Figure 3.

Several long term follow-up and secondary analyses of the TRACE study have addressed additional aspects of



No at Risk

$\begin{array}{llllll}\text { Trandolapril } & 876 & 677 & 618 & 319 & 20\end{array}$

$\begin{array}{llllll}\text { Placebo } & 873 & 647 & 562 & 280 & 22\end{array}$

Figure 2 Cumulative mortality from all causes among patients receiving trandolapril or placebo. Reprinted with permission from Kober L, Torp-Pedersen C, Carlsen JE, et al 1995. A clinical trial of the angiotensin-converting-enzyme inhibitor trandolapril in patients with left ventricular dysfunction after myocardial infarction. Trandolapril Cardiac Evaluation (TRACE) Study Group. N Engl J Med, 333:1670-6. Copyright (C) 1995 Massachusetts Medical Society.All rights reserved.

trandolapril use after AMI. First, the prognostic importance of atrial fibrillation (AF) development and the impact of trandolapril have been studied. Of all patients enrolled (trial or registry), sustained or paroxysmal AF or atrial flutter (AFL) was observed in 1149 patients (19\%) during hospitalization (Pedersen et al 2006). During follow-up, 1659 patients (34\%) in the registry died: $482(50 \%)$ patients with AF/AFL and 1177 (30\%) patients without AF/AFL, $p<0.001$. Sudden cardiac death (SCD) occurred in 536, non-SCD occurred in 725 , and 398 died of non-cardiovascular causes (including 142 unclassifiable cases). The adjusted risk ratio of $\mathrm{AF} / \mathrm{AFL}$ for total mortality was 1.33 (95\% CI 1.19-1.49; $p<0.0001$ ), 1.31 for SCD $(95 \%$ CI $1.07-1.60, \mathrm{p}<0.009)$ and 1.43 for non-SCD (95\% CI 1.21-1.70, $\mathrm{p}<0.0001)$. Therefore, after an $\mathrm{AMI}, \mathrm{AF} / \mathrm{AFL}$ are associated with increased mortality, both from SCD and non-SCD (Pedersen et al 2006). In the TRACE study, AF developed in only $2.8 \%$ of patients receiving trandolapril compared with $5.3 \%$ in the placebo group $(p<0.05)$, even after multivariate analyses (Pedersen et al 1999). More recently, ACE inhibition has been shown to prevent new-onset $\mathrm{AF}$, facilitate direct current cardioversion and maintain sinus rhythm (Kalus et al 2006). A complete discussion on this topic is beyond the scope of this article and may be found elsewhere (Palardy and Ducharme 2005). 

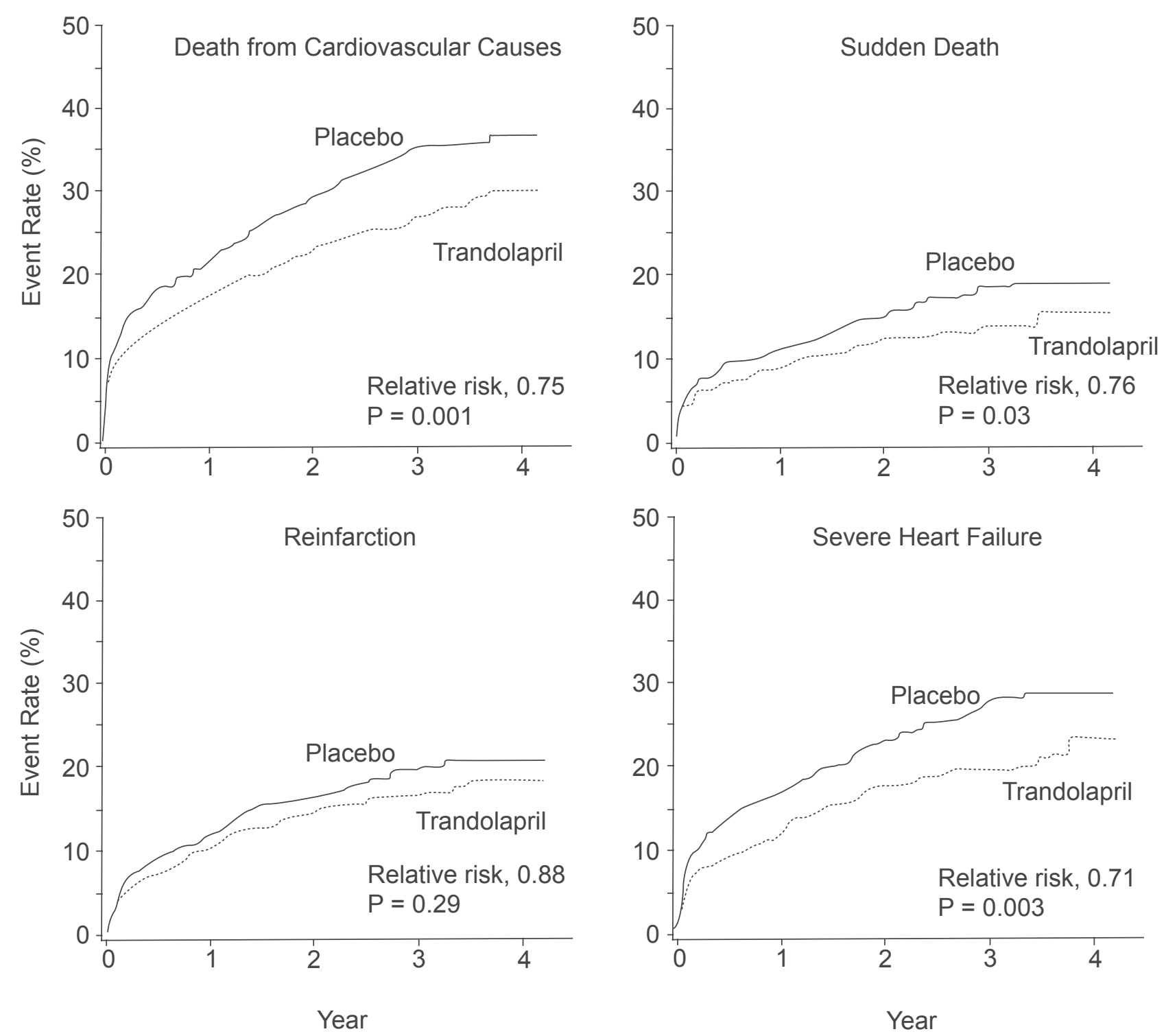

Figure 3 Event rates for the secondary end points of death from cardiovascular causes, sudden death, reinfarction and severe or resistant heart failure among patients receiving trandolapril or placebo. Reprinted with permission from Kober L, Torp-Pedersen C, Carlsen JE, et al I995. A clinical trial of the angiotensin-converting-enzyme inhibitor trandolapril in patients with left ventricular dysfunction after myocardial infarction. Trandolapril Cardiac Evaluation (TRACE) Study Group. N Engl J Med, 333:I670-6. Copyright (C) 1995 Massachusetts Medical Society. All rights reserved.

Most of the data on ACE inhibition and heart failure after AMI have limited follow-up duration, owing to the nature of randomized trials. An extended follow-up from TRACE (Buch et al 2005) has been published, focusing on long term survival (more than 10 years) and hospital admission occurring during and beyond the randomized phase of the study. The mortality curves between patients initially allocated to trandolapril or placebo started to diverge during the first year, favoring trandolapril, and remained thereafter. The Kaplan-Meier estimate of mortality at 10 years was $71.5 \%$ in the placebo group and $69.5 \%$ in the trandolapril group. For the entire follow-up, trandolapril significantly reduced the risk of death from any cause compared with placebo (RR 0.89,
95\% CI 0.80-0.99, $\mathrm{p}=0.031$ ) (Figure 4), all causes hospital admissions (RR 0.92, 95\% CI 0.88-0.96, p < 0.001) and cardiac hospitalizations (RR 0.95, 95\% CI 0.91-1.00, p=0.047), the majority being for heart failure (Buch et al 2005). These data suggest an early benefit of ACE inhibition after AMI and persistent effects over time, beyond the randomized trial duration, a period after which most patients initially allocated to placebo will have been switched to an ACE inhibitor.

\section{Diabetic patients with left- ventricular dysfunction after $\mathrm{MI}$}

A growing body of evidence indicates that regulation of the rennin-angiotensin system is important for the prevention of 


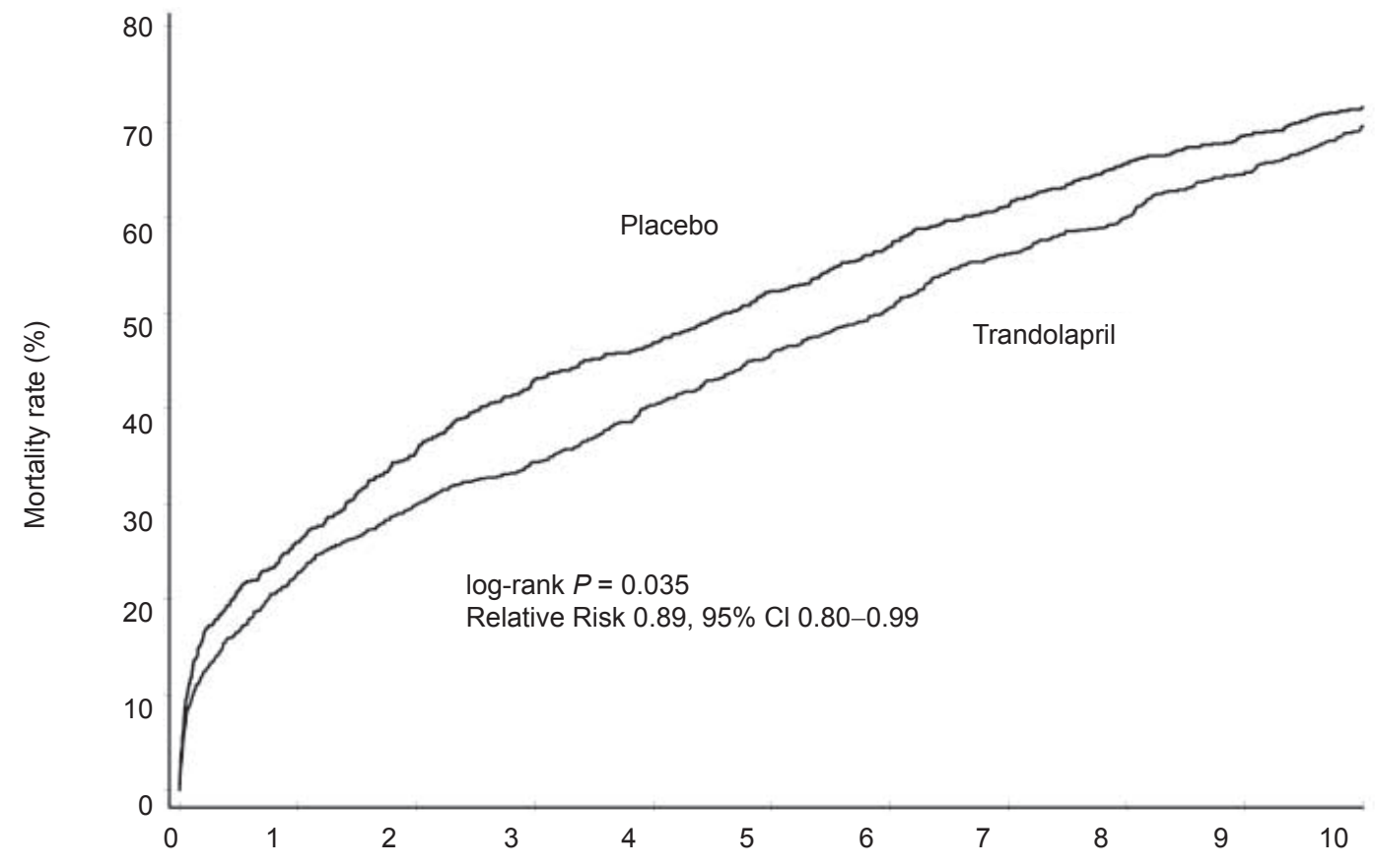

\section{No patients at risk}

$\begin{array}{llllllllllll}\text { Trandolapril } & 876 & 677 & 615 & 576 & 524 & 475 & 434 & 385 & 351 & 310 & 265 \\ \text { Placebo } & 873 & 647 & 564 & 497 & 463 & 417 & 398 & 338 & 299 & 273 & 245\end{array}$

Figure 4 Cumulative mortality from all causes in the trandolapril group compared with the placebo group over 10 years of follow-up. Reprinted with permission from Buch P, Rasmussen S, Abildstrom SZ, et al 2005. The long-term impact of the angiotensin-converting enzyme inhibitor trandolapril on mortality and hospital admissions in patients with left ventricular dysfunction after a myocardial infarction: follow-up to 12 years. Eur Heart J, 26: I45-52. Copyright @ 2005 European Society of Cardiology.

cardiovascular events, not only in hypertensive patients, but also in diabetics; they are considered high risk with markedly increased mortality after AMI, almost double that of patients without diabetes. This excess mortality seems to be related to congestive heart failure and reinfarction episodes (Zuanetti et al 1993; Granger et al 1993; Malmberg et al 1996; Mak et al 1997). ACE inhibition is beneficial in these patients, mainly through prevention of LV remodeling (Cohn et al 2000). Other mechanisms have also been suggested such as improvement in: fibrinolytic balance, endothelial function, sympatho-vagal balance and glycemic control, in addition to preservation of renal function (Gustafsson et al 1999).

A subgroup analysis of diabetics patients enrolled in TRACE showed that ACE inhibition with trandolapril is beneficial in this population. As previously mentioned, diabetic patients had a worse prognosis than non-diabetic patients, but prognosis was improved with ACE inhibitor treatment, with a RR for total mortality of 0.64 (95\% CI: 0.45-0.91) compared with placebo, after multivariate analysis including age, gender, body mass index, smoking, previous MI, hypertension, AF, CHF, residual angina and WMSI (Gustafsson et al 1999) (Figure 5). Interestingly, in diabetics treatment with trandolapril compared to placebo reduced all secondary endpoints by approximately 50\%. Of particular interest was the marked reduction in the progression toward severe heart failure with trandolapril $(\mathrm{RR}=0.38,95 \% \mathrm{CI}$ : $0.21-0.67)$. For the non-diabetic patients, only cardiovascular death was reduced significantly with ACE inhibitor treatment (RR 0.79, 95\% CI 0.66-0.96).

In a small randomized trial of type 2 diabetes patients, coronary flow velocity reserve improved after treatment with an ACE inhibitor but not with an angiotensin-II receptor antagonist, suggesting that ACE inhibition might have beneficial effects on coronary microangiopathy associated with type 2 diabetes (Kawata et al 2006). In an experimental model of diabetes, this condition was associated with decreased myocardial capillary supply, which was reversed by ACE inhibition, but not by endothelin-1 receptor blockade. 

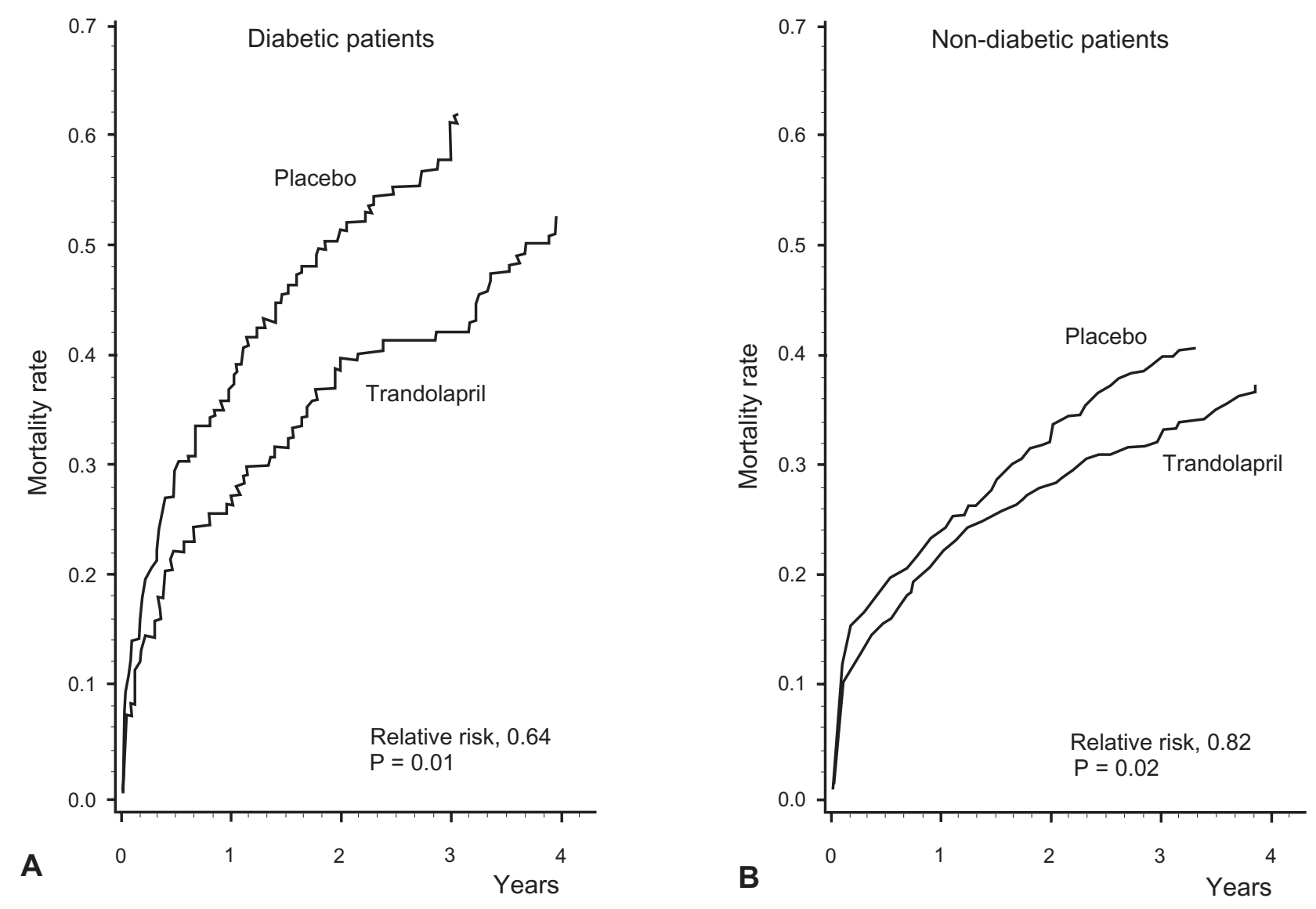

Figure 5 Cumulative mortality from all causes for patients with (A) and without (B) diabetes receiving trandolapril or placebo. Reprinted with permission from Gustafsson F, Torp-Pedersen C, Kober L, et al 1997. Effect of angiotensin converting enzyme inhibition after acute myocardial infarction in patients with arterial hypertension. TRACE Study Group, Trandolapril Cardiac Event.J Hypertens, 15:793-8. Copyright @ 1997 Lippincott Williams \& Wilkins.

Attenuation of cardiac fibrosis deposition with ACE inhibitor was also seen (Gross et al 2004).

The prognostic importance of optimal glycaemia control has been recently recognized. Hence the effects on glucose metabolism of the beta-blocker atenolol and the ACE inhibitor trandolapril were investigated in patients with primary hypertension, using a small, randomized, double-blind, parallel-group design. After 48 weeks of treatment, insulin sensitivity was reduced by $23 \%$ using atenolol, while it remained unchanged with trandolapril $(+0.5 \%, \mathrm{p}=0.0010)$ (Reneland et al 2000). Although interesting, the subject remains highly controversial (Petrie et al 2000; New et al 2000). Nevertheless, there is additional evidence that ACE inhibitor with trandolapril improves the progression of diabetic peripheral neuropathy (Malik et al 1998; Stoschitzky 1999; Malik 2000).

\section{ACE inhibition in stable coronary artery disease}

The concept of vascular protection has been proposed after retrospective analysis from both SOLVD and SAVE has suggested reduced recurrent $\mathrm{MI}$ in HF patients allocated to ACE inhibitor compared with placebo. Hence large scale trials have been designed to test this hypothesis. The first two trials with ACE inhibitors have been undertaken in high-risk patients with either coronary artery disease (CAD) without symptomatic heart failure, pre-existing vascular disease, or diabetes combined with an additional cardiovascular risk factor. In these situations, ACE inhibition with ramipril or perindopril leads to reduced rates of the combined endpoint of death from cardiovascular causes, acute MI or stroke in the Heart Outcomes Prevention Evaluation (HOPE) trial (Yusuf et al 2000) or the combined endpoint of cardiovascular death, MI, or cardiac arrest in the European Trial on Reduction of Cardiac Events with Perindopril in Stable Coronary Artery Disease (EUROPA) trial (Fox 2003). These two trials are similar and enrolled patients at increased risk of adverse cardiovascular events. Although patients with symptomatic heart failure were excluded from these trials, there was no requirement for $\mathrm{LV}$ ejection fraction measurement and the brain natriuretic peptide biomarker was not available at that 
time. Nevertheless, the concept of vascular protection with ACE inhibitor was supported by these studies.

The goal of the Prevention of Events with Angiotensin Converting Enzyme Inhibition (PEACE) trial was to test whether ACE inhibitor therapy, when added to modern conventional therapy, would reduce the rate of non-fatal MI, death from cardiovascular causes, or revascularization in patients with stable coronary artery disease and normal or slightly reduced LV function (Braunwald et al 2004). PEACE enrolled patients aged 50 years or older with coronary artery disease documented by at least one of the following: MI at least 3 months before enrolment; coronary-artery bypass grafting or percutaneous transluminal coronary angioplasty at least 3 months before enrolment; obstruction of $\geq 50 \%$ of the luminal diameter of at least one native vessel on coronary angiography and left ventricular ejection fraction $>40 \%$ on contrast or radionuclide ventriculography or echocardiography; a qualitatively normal left ventriculogram; or the absence of LV wall-motion abnormalities on echocardiography. Patients hospitalized for angina within the preceding 2 months were excluded as well as any other unstable cardiac or non-cardiac condition. The original endpoint was reduction in cardiovascular death or non-fatal MI, and required a sample size of 14,100 patients. Due to recruiting difficulties, this primary endpoint was changed by the steering committee, to include coronary revascularization, which reduced the sample size to 8100 . The original primary endpoint became a secondary endpoint. Of the 8290 patients who underwent randomization, 4158 were assigned to receive trandolapril and 4132 matching placebo. Compliance with the target trandolapril dose (4 mg) was $68.4 \%$ in the treatment group and $77.7 \%$ in the placebo group. The median followup was 4.8 years. Baseline characteristics include patients' mean ( \pm SD) age of $64 \pm 8$ years and $18 \%$ of patients enrolled were women. $55 \%$ had a previous MI, $72 \%$ had undergone at least one coronary-revascularization procedure, and $17 \%$ were known to have diabetes. A quantitative ejection fraction was available for $95 \%$ of the cohort, with a mean value of $58 \pm 9 \%$; for the remaining $5 \%$, a two-dimensional echocardiogram reported normal LV function by qualitative assessment. $70 \%$ of patients were using lipid-lowering drugs. The average serum cholesterol concentration was $192 \mathrm{mg} / \mathrm{dL}$ ( $5 \mathrm{mmol} / \mathrm{L}$ ) (Braunwald et al 2004). The incidence of the new primary endpoint was $22.5 \%$ in the placebo group and $21.9 \%$ in the trandolapril group (HR 0.96, 95\% CI 0.88-1.06, $\mathrm{p}=0.43$ ) (Braunwald et al 2004) (Figure 6). Side effects leading to discontinuation of the study medication occurred in $6.5 \%$ of the patients in the placebo group and $14.4 \%$ of

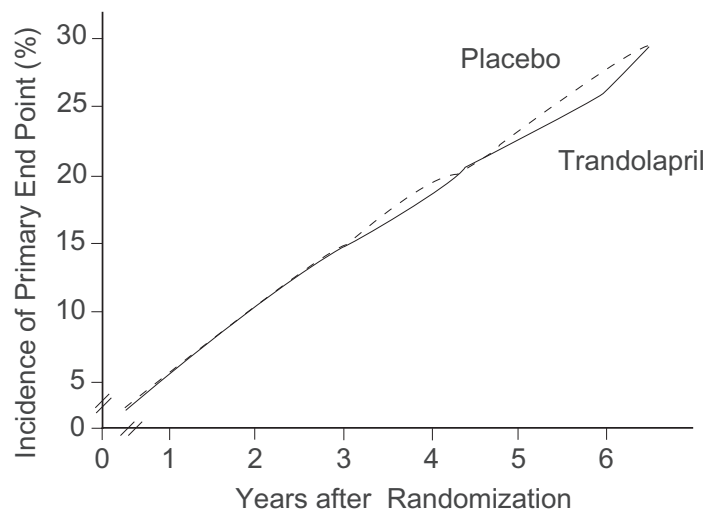

No at Risk

Trandolapril 41584017 $3752 \quad 3506 \quad 3079 \quad 1963 \quad 969$

$\begin{array}{lllllll}\text { Placebo } & 41323990 & 3719 & 3486 & 3027 & 1929 & 891\end{array}$

Figure 6 Cumulative incidence of primary endpoint, according to treatment allocation. Reprinted with permission from Braunwald E, Domanski MJ, Fowler SE, et al 2004. Angiotensin-converting-enzyme inhibition in stable coronary artery disease. N Engl J Med, 351:2058-68. Copyright 2004 @ Massachusetts Medical Society. All rights reserved.

those in the trandolapril group ( $\mathrm{p}<0.001)$, mainly due to cough $(39.1 \%$ vs $27.5 \%, \mathrm{p}<0.01)$ and syncope $(4.8 \%$ vs $3.9 \%, \mathrm{p}=0.04$ ), which were higher in the trandolapril group (Braunwald et al 2004). Angioedema was reported in 5 patients in the placebo group ( 2 were openly taken ACE inhibitors) and in 8 patients in the trandolapril group.

Compared with previous studies, patients in the PEACE trial were at lower risk of death from cardiovascular causes, non-fatal MI or stroke than patients enrolled in the HOPE or EUROPA trials, as can be appreciated in Figure 7. This might, in part, explain the neutral results of this large trial. Moreover, patients in the PEACE trial were more aggressively treated (more previous revascularization and more intensive management of risk factors) than patients in the previous trials. In particular, the level of LDL cholesterol and lipid lowering treatment used (statins) are important. ACE inhibitors and statins have a common mechanism of

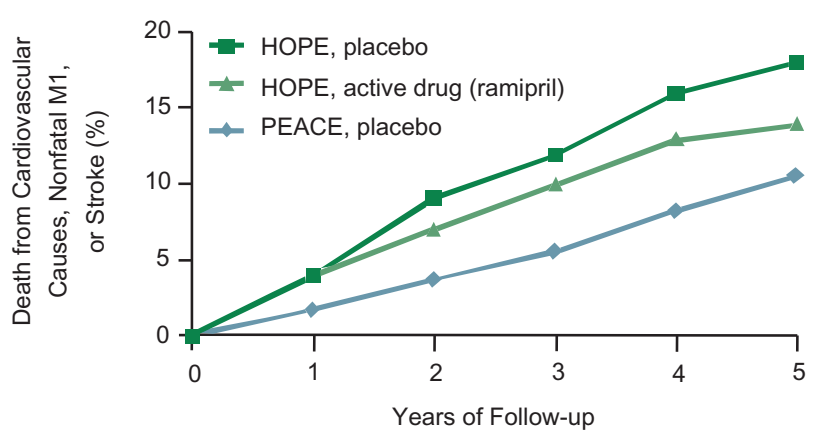

Figure 7 Comparisson of outcomes in the PEACE trial and HOPE. 
action: they both reduce activation of the lectin-like oxidized LDL receptor and thus reduce oxidation of LDL cholesterol. If the concentration of LDL cholesterol is sufficiently low, ACE inhibitors may no longer be effective in reducing the rate of cardiovascular events (Pitt 2004).

In spite of these neutral results, current guidelines recommend $\mathrm{ACE}$ inhibition in $\mathrm{CAD}$ patients with other indications for these agents, such as hypertension, LV systolic dysfunction with/without prior MI, symptomatic heart failure or diabetes (Anderson et al 2007). In revascularized CAD patients treated with aspirin and statins, and no formal indication for ACE inhibitor treatment, the benefit should perhaps be weighed against the cost, risk and side effects.

\section{Patients with hypertension}

ACE inhibitors have been used since the 1970s for the treatment of hypertension (HTN). Their advantage in this population not only lies in secondary beneficial effects of reduction in levels of angiotensin-II, but also in decreased catecholamine levels and vascular remodelling, among others. Trandolapril has been approved by the US Food and Drug Administration in the US in 1996 and in Canada in 1997 for the treatment of patients with mild to moderate hypertension. Many controlled clinical trials have found that trandolapril, alone or in combination with other antihypertensive agents, produces clinically significant blood pressure (BP) reductions and achieves target BP levels in patients with primary HTN (Mancia et al 1992; Guller et al 1993; Cesarone et al 1994; Omboni et al 1995; Guay 2003; Pepine et al 2003; Tytus et al 2007)

TRAIL (The Canadian Study of Trandolapril on Blood Pressure in Hypertensive Patients) was a 26-week, prospective, open-label, multicenter study in Canadian primary care centers (Tytus et al 2007). Subjects with HTN stages I and II according to the 7-JNC (Chobanian et al 2003) who were treatment naive or whose disease was uncontrolled on current first-line antihypertensive monotherapy, were treated with trandolapril alone or in addition to their current regimen. Trandolapril was started at $1 \mathrm{mg}$ and was titrated to 2 or $4 \mathrm{mg}$. The purpose of the study was to evaluate the effectiveness of escalating-dose regimen of trandolapril in HTN management. In the total cohort, $71 \%$ of patients reached adequate BP control according current guidelines $(<140 / 90 \mathrm{mmHg}$ in subjects with no other risk factors and $<130 / 80 \mathrm{mmHg}$ in patients with kidney disease or diabetes) after 2 weeks of treatment and 73.4\% after 26 weeks. Optimal BP control was equally achieved in naive patients as well as in patients already treated but with sub-optimal BP control.
INVEST (The INternational VErapamil-Trandolapril Study) was a randomized, open label study of 22,576 hypertensive CAD patients aged 50 years or older, conducted from September 1997 to February 2003 at 862 sites in 14 countries (Pepine et al 2003). The combined primary endpoint was death (all cause), or first occurrence of non-fatal MI or non-fatal stroke. Other endpoints included cardiovascular death, angina, adverse reactions, hospitalizations, and blood pressure control at 24 months. Patients were randomly assigned to verapamil sustained release or atenolol. Subsequently, trandolapril (for the calcium channel blocker [CCB] group) and hydrochlorothiazide (for the beta blocker [BB] group) were added if needed to achieve BP target levels according to the 6-JNC guidelines. Trandolapril was also recommended when there was a clear clinical indication such as for patients with heart failure, diabetes or renal impairment. The mean follow-up was 2.7 years. A primary outcome event occurred in $9.93 \%$ of the patients in the CCB group vs $10.17 \%$ in the BB group, with a RR of 0.98 (95\% CI 0.90-1.06). Twoyear BP control was similar in the two groups, demonstrating that the verapamil-trandolapril strategy was as effective as the atenolol-hydrochlorothiazide strategy. The INVEST trial was designed to have a short follow-up which may explain the lack of statistical power to demonstrate a reduction in hard endpoints.

A retrospective analysis from TRACE on the subgroup of patients with hypertension confirmed the worse prognosis of HTN after AMI compared with patients without HTN (Gustafsson et al 1997). 173 patients (43\%) with a medical history of hypertension at randomization (the hypertensive group) died during follow-up, versus 500 (37\%) without HTN history. Of note, treatment with trandolapril resulted in a profound beneficial effect in this population, with a RR of death from any cause for the hypertensive group of 0.59 (95\% CI 0.44-0.80) in the trandolapril group compared with placebo, versus 0.85 (95\% CI 0.72-1.02) for normotensive patients allocated to the ACE inhibitor (Gustafsson et al 1997). The interaction between the diagnosis of HTN and the benefit of trandolapril treatment was highly significant $(\mathrm{p}<0.001)$ (Gustafsson et al 1997).

\section{Prevention of proteinuria}

Many trials have shown that not only inadequate diabetes control (reflected by elevated glycosylated hemoglobin), but also hypertension, dyslipidemia, cigarette smoking, old age, insulin resistance, male sex, and afro-Caribbean, Asian or native American origin are strong risk factors for the development of diabetic nephropathy (Gall et al 1991; 
Keller et al 1996; Ravid et al 1998). In normal subjects, an elevated preglomerular vascular resistance protects the glomerular microcirculation from systemic BP variations. In patients with diabetic nephropathy, this protective mechanism is blunted and vasodilatation of the afferent (preglomerular) vessels occurs, permitting the systemic BP variation to be transmitted to the glomerular bed. Hence, strict BP control is mandatory in these patients in order to avoid further glomerular damage. In diabetic nephropathy, typical histological progressive changes in the glomerular structure can be found, which leads at first to microalbuminuria, followed by selective albuminuria and later on to nonselective protein excretion with a progressive decline in renal function and end-stage renal failure.

Microalbuminuria has been extensively studied as a risk factor for cardiovascular outcomes, mostly in patients with diabetes mellitus (Sarnak et al 2003). This association has been also observed in patients with vascular diseases (Gerstein et al 2001), electrocardiographic ST-T segment changes (Diercks et al 2002) and those with hypertension (Ljungman et al 1996; Agewall et al 1997; De Leeuw et al 2002). At first, it was thought that proteinuria reduction and renal protection induced by ACE inhibitors were primarily due to vasodilatation of the efferent arteriole with subsequent decrease in glomerular capillary pressure (Miettinen et al 1996). However, ACE inhibitors play an additional role in glomerular function by modifying glomerular size and permeability and increasing negative electric charge in the glomerular membrane (Amann et al 1993, Remuzzi et al 1990).

The MIcroalbuminuria, Cardiovascular, and Renal Outcomes in HOPE (MICRO-HOPE) substudy showed that ramipril treatment was associated with a decreased risk of development of overt nephropathy in patients enrolled in HOPE and evidence of microalbuminuria at baseline (HOPE Study Investigators 2000). Likewise, the BENEDICT (BErgamo NEphrologic DIabetes Complications Tial) evaluated whether a combination therapy of ACE inhibitor and $\mathrm{CCB}$ was better than either class alone or placebo in decreasing the progression toward microalbuminuria in normoalbuminuric patients with type 2 diabetes and hypertension (Ruggenenti et al 2004). In BENEDICT, 1204 patients were randomized to either a combination of trandolapril and verapamil, trandolapril alone, verapamil alone or placebo. Median follow-up was 3.6 years. A total of 601 subjects received an ACE inhibitor (alone or with verapamil) and 603 subjects did not. Persistent microalbuminuria, the primary endpoint, was reached in 35 (5.8\%) subjects who received an ACE inhibitor-based therapy and in $66(10.9 \%)$ in subjects who did not. This difference was statistically significant $(\mathrm{p}<0.001)$ even after adjustment for site, age, sex, smoking status, diastolic BP and log-transformed urinary albumin excretion at baseline (Figure 8). At the end of the study, patients in the trandolapril group (alone or in combination with verapamil) had a lower BP than patients in the verapamil group alone.

The PROCOPA study was designed to compare whether the magnitude of proteinuria reduction with different classes of anti-hypertensive agents differs, while similar BP reduction is achieved (PROCOPA 2002). It was a prospective, randomized, double-blind, controlled trial. Inclusion criteria included: $\mathrm{BP}>130 / 85 \mathrm{mmHg}$, primary renal disease, proteinuria $>1 \mathrm{~g} /$ day and creatinine clearance $\geq 50 \mathrm{~mL} / \mathrm{min}$.

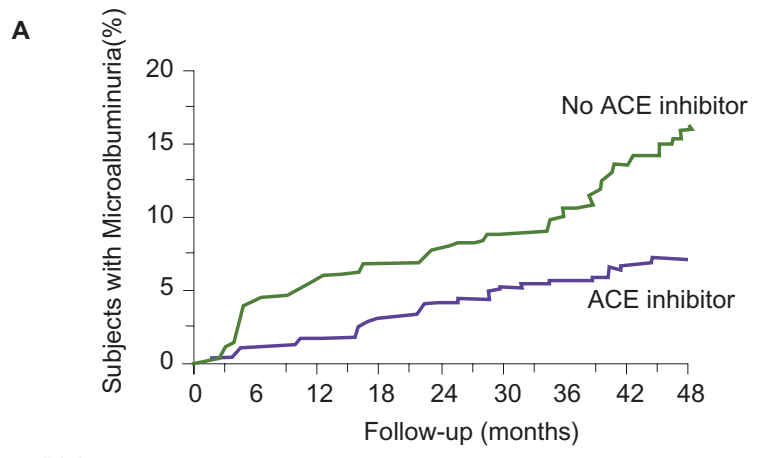

No at Risk

ACE inhibitor $\quad \begin{array}{lllllllll}601 & 503 & 469 & 441 & 417 & 399 & 380 & 311 & 220\end{array}$ No ACE inhibitor $\begin{array}{lllllllll}603 & 463 & 424 & 405 & 375 & 357 & 338 & 270 & 188\end{array}$

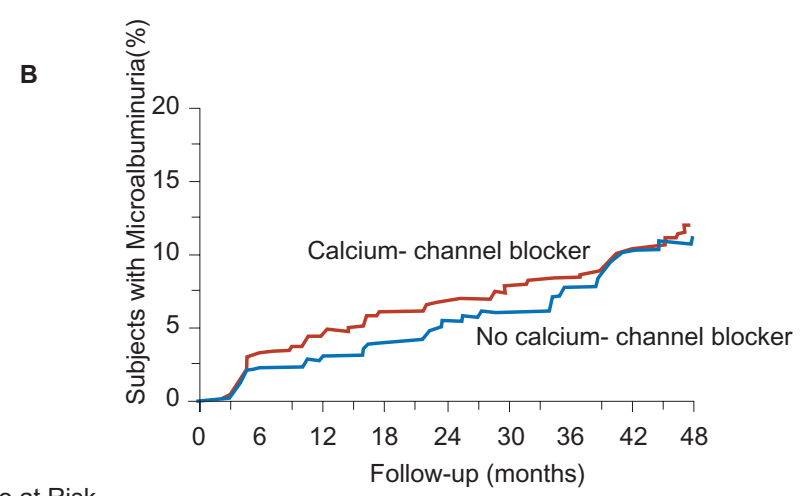

No at Risk

Calcium-channel $\begin{array}{lllllllll}603 & 483 & 442 & 419 & 399 & 382 & 366 & 296 & 214\end{array}$ blocker

$\begin{array}{llllllllll}\text { No calcium- } & 601 & 483 & 451 & 27 & 394 & 374 & 352 & 285 & 194\end{array}$ channel blocker

Figure 8 Kaplan-Meier Curves for the Percentages of Subjects with Microalbuminuria during Treatment with or without ACE Inhibitors (Panel A) and with or without Non-Dihydropyridine Calcium-Channel Blockers (Panel B). The difference between the group that received ACE inhibitor therapy and the group that did not, adjusted for prespecified baseline covariates (see text) was significant $(p<0.00 \mathrm{I})$ according to the accelerated failure-time model. The difference between the group that received non-dihydropyridine calcium-channel blockers and the group that did not was not significant $(P=0.92)$. Reprinted with permission from Ruggenenti P, Fassi A, Ilieva AP, et al 2004. Preventing microalbuminuria in type 2 diabetes. N Engl J Med, 35I:194I-5I. Copyright 2004 (c) Massachusetts Medical Society. All rights reserved. 
After a run-in period, patients were randomized to atenolol, trandolapril, verapamil or a combination of verapamil and trandolapril for 6 months. There was no statistically significant difference in BP control between groups. However, a significant fall in protein urinary excretion was obtained in the ACE inhibitor-based strategy (both trandolapril/verapamil combination and trandolapril-alone groups), suggesting that in spite of adequate and similar BP control provided by the four classes of agents, only ACE inhibition reduces proteinuria in primary renal disease. No angiotensin-II receptor blockers were included in this trial.

\section{Advantages of trandolapril over other ACE inhibitors}

Appropriate, recommended and optimal dosage with ACE inhibitors is becoming more prominent in cardiovascular literature (Furberg and Pitt 2001; Hansen et al 2008). There is solid evidence from pharmacokinetic and hard endpoint clinical trials for the optimal trandolapril dosage to use. Despite the fact that most ACE inhibitors are recommended for once-daily administration, only fosinopril, ramipril and trandolapril have trough-to-peak effect ratios in excess of 50\% (Song and White 2002). Other ACE inhibitors, such as perindopril, have obtained indication for heart failure with a dosage of $4 \mathrm{mg}$ daily, but should it be $8 \mathrm{mg}$ or even $16 \mathrm{mg}$ per day? Current US guidelines for the management of chronic heart failure acknowledge this problem and they do not establish a precise recommended dosage for enalapril, lisinopril or perindopril (Hunt et al 2005). The task force for the diagnosis and treatment of chronic heart failure of the European Society of Cardiology also leave the clinician with this dilemma. Therefore in Europe, only enalapril (10 mg twice a day) and trandolapril (4 mg daily) have precise recommended evidence-based dosage (Swedberg et al 2005).

\section{Conclusion}

Trandolapril is a well studied, safe and effective ACE inhibitor with clinically convenient pharmacological properties. It is widely used in the management of cardiovascular disorders in different populations, such as patients with hypertension and diabetic patients with coronary artery disease, and especially in the prevention and management of proteinuria. Particularly, there is a sound evidence-based support for trandolapril $4 \mathrm{mg}$ once a day in post-MI patients with LV dysfunction regardless of heart failure symptoms.

\section{Acknowledgments}

Dr Ducharme is supported by the Fonds de Recherche en Santé du Québec (FRSQ).

\section{Disclosures}

The authors have no conflicts of interest to disclose.

\section{References}

Agewall S, Wikstrand J, Ljungman S, et al. 1997. Usefulness of microalbuminuria in predicting cardiovascular mortality in treated hypertensive men with and without diabetes mellitus. Risk Factor Intervention Study Group. Am J Cardiol, 80:164-9.

Amann K, Irzyniec T, Mall G, et al. 1993. The effect of enalapril on glomerular growth and glomerular lesions after subtotal nephrectomy in the rat: a stereological analysis. J Hypertens, 11:969-75.

Anderson JL, Adams CD, Antman EM, et al. 2007. ACC/AHA 2007 guidelines for the management of patients with unstable angina/ non-ST-Elevation myocardial infarction: a report of the American College of Cardiology/American Heart Association Task Force on Practice Guidelines (Writing Committee to Revise the 2002 Guidelines for the Management of Patients With Unstable Angina/ Non-ST-Elevation Myocardial Infarction) developed in collaboration with the American College of Emergency Physicians, the Society for Cardiovascular Angiography and Interventions, and the Society of Thoracic Surgeons endorsed by the American Association of Cardiovascular and Pulmonary Rehabilitation and the Society for Academic Emergency Medicine. J Am Coll Cardiol, 50:e1-e157.

Arner P, Wade A, Engfeldt P, et al. 1994. Pharmacokinetics and pharmacodynamics of trandolapril after repeated administration of $2 \mathrm{mg}$ to young and elderly patients with mild-to-moderate hypertension. J Cardiovasc Pharmacol, 23(Suppl 4):S44-9.

Aurell M. 1998. The renin-angiotensin system: the centenary jubilee. Blood Press, 7:71-5.

Braunwald E, Domanski MJ, Fowler SE, et al. 2004. Angiotensinconverting-enzyme inhibition in stable coronary artery disease. $N$ Engl J Med, 351:2058-68.

Buch P, Rasmussen S, Abildstrom SZ, et al. 2005. The long-term impact of the angiotensin-converting enzyme inhibitor trandolapril on mortality and hospital admissions in patients with left ventricular dysfunction after a myocardial infarction: follow-up to 12 years. Eur Heart $J, 26: 145-52$.

Cesarone MR, De Sanctis MT, Laurora G, et al. 1994. Effects of trandolapril on 24-h ambulatory blood pressure in patients with mild-to-moderate essential hypertension. J Cardiovasc Pharmacol, 23(Suppl 4):S65-72.

Chobanian AV, Bakris GL, Black HR, et al. 2003. The Seventh Report of the Joint National Committee on Prevention, Detection, Evaluation, and Treatment of High Blood Pressure: the JNC 7 report. JAMA, 289:2560-72.

Cohn JN, Ferrari R, Sharpe N. 2000. Cardiac remodeling - concepts and clinical implications: a consensus paper from an international forum on cardiac remodeling. Behalf of an International Forum on Cardiac Remodeling. J Am Coll Cardiol, 35:569-82.

Danielson B, Querin S, Larochelle P, et al. 1994. Pharmacokinetics and pharmacodynamics of trandolapril after repeated administration of $2 \mathrm{mg}$ to patients with chronic renal failure and healthy control subjects. $J$ Cardiovasc Pharmacol, 23(Suppl 4):S50-9.

De Leeuw PW, Thijs L, Birkenhager WH, et al. 2002. Prognostic significance of renal function in elderly patients with isolated systolic hypertension: results from the Syst-Eur trial. J Am Soc Nephrol, 13:2213-22.

De Luca N, Rosiello G, Lamenza F, et al. 1992. Reversal of cardiac and large artery structural abnormalities induced by long-term antihypertensive treatment with trandolapril. Am J Cardiol, 70:52D-59D. 
Diercks GF, Hillege HL, Van Boven AJ, et al. 2002. Microalbuminuria modifies the mortality risk associated with electrocardiographic ST-T segment changes. J Am Coll Cardiol, 40:1401.

Fox KM. 2003. Efficacy of perindopril in reduction of cardiovascular events among patients with stable coronary artery disease: randomised, double-blind, placebo-controlled, multicentre trial (the EUROPA study). Lancet, 362:782-8.

Furberg CD, Pitt B. 2001. Are all angiotensin-converting enzyme inhibitors interchangeable? J Am Coll Cardiol, 37:1456-60.

Gall MA, Rossing P, Skott P, et al. 1991. Prevalence of micro- and macroalbuminuria, arterial hypertension, retinopathy and large vessel disease in European type 2 (non-insulin-dependent) diabetic patients. Diabetologia, 34:655-61.

Gerstein HC, Mann JF, Yi Q, et al. 2001. Albuminuria and risk of cardiovascular events, death, and heart failure in diabetic and nondiabetic individuals. JAMA, 286:421-6.

Granger CB, Califf RM, Young S, et al. 1993. Outcome of patients with diabetes mellitus and acute myocardial infarction treated with thrombolytic agents. The Thrombolysis and Angioplasty in Myocardial Infarction (TAMI) Study Group. J Am Coll Cardiol, 21:920-5.

Gross ML, Heiss N, Weckbach M, et al. 2004. ACE-inhibition is superior to endothelin A receptor blockade in preventing abnormal capillary supply and fibrosis of the heart in experimental diabetes. Diabetologia, 47:316-24.

Guay DRP. 2003. Trandolapril: A newer angiotensin-converting enzyme inhibitor. Clin Ther, 25:713-75.

Guller B, Hall J, Reeves RL. 1993. Cardiac effects of trandolapril in hypertension. Am Heart J, 125:1536-41.

Gustafsson F, Torp-Pedersen C, Kober L, et al. 1997. Effect of angiotensin converting enzyme inhibition after acute myocardial infarction in patients with arterial hypertension. TRACE Study Group, Trandolapril Cardiac Event. J Hypertens, 15:793-8.

Gustafsson I, Torp-Pedersen C, Kober L, et al. 1999. Effect of the angiotensin-converting enzyme inhibitor trandolapril on mortality and morbidity in diabetic patients with left ventricular dysfunction after acute myocardial infarction. Trace Study Group. J Am Coll Cardiol, 34:83-9.

Hansen ML, Gislason GH, Kober L, et al. 2008. Different angiotensinconverting enzyme inhibitors have similar clinical efficacy after myocardial infarction. Br J Clin Pharmacol, 65:217-23.

Hedner T, Hansson L, Himmelmann A. 1998. The renin-angiotensin system - a century of progress. Blood Press, 7:68-70.

Heger JJ, Weyman AE, Wann LS, et al. 1980. Cross-sectional echocardiographic analysis of the extent of left ventricular asynergy in acute myocardial infarction. Circulation, 61:1113-8.

HOPE Study Investigators. 2000. Effects of ramipril on cardiovascular and microvascular outcomes in people with diabetes mellitus: results of the HOPE study and MICRO-HOPE substudy. Heart Outcomes Prevention Evaluation Study Investigators. Lancet, 355:253-9.

Hunt SA, Abraham WT, Chin MH, et al. 2005. ACC/AHA 2005 Guideline Update for the Diagnosis and Management of Chronic Heart Failure in the Adult: a report of the American College of Cardiology/American Heart Association Task Force on Practice Guidelines (Writing Committee to Update the 2001 Guidelines for the Evaluation and Management of Heart Failure): developed in collaboration with the American College of Chest Physicians and the International Society for Heart and Lung Transplantation: endorsed by the Heart Rhythm Society. Circulation, 112:e154-235.

Kalus JSColeman CI, White CM. 2006. The impact of suppressing the renin-angiotensin system on atrial fibrillation. J Clin Pharmacol, $46: 21-8$

Kawata T, Daimon M, Hasegawa R, et al. 2006. Effect on coronary flow velocity reserve in patients with type 2 diabetes mellitus: comparison between angiotensin-converting enzyme inhibitor and angiotensin II type 1 receptor antagonist. Am Heart J, 151:798 e9-15.

Keller CK, Bergis KH, Fliser D, et al. 1996. Renal findings in patients with short-term type 2 diabetes. J Am Soc Nephrol, 7:2627-35.
Kober L, Torp-Pedersen C, Carlsen JE, et al. 1995. A clinical trial of the angiotensin-converting-enzyme inhibitor trandolapril in patients with left ventricular dysfunction after myocardial infarction. Trandolapril Cardiac Evaluation (TRACE) Study Group. $N$ Engl $J$ Med, 333:1670-6.

Ljungman S, Wikstrand J, Hartford M, et al. 1996. Urinary albumin excretion - a predictor of risk of cardiovascular disease. A prospective 10-year follow-up of middle-aged nondiabetic normal and hypertensive men. Am J Hypertens, 9:770-8.

Mak KH, Moliterno DJ, Granger CB, et al. 1997. Influence of diabetes mellitus on clinical outcome in the thrombolytic era of acute myocardial infarction. GUSTO-I Investigators. Global Utilization of Streptokinase and Tissue Plasminogen Activator for Occluded Coronary Arteries. $J$ Am Coll Cardiol, 30:171-9.

Malik RA. 2000. Can diabetic neuropathy be prevented by angiotensinconverting enzyme inhibitors? Ann Med, 32:1-5.

Malik RA, Williamson S, Abbott C, et al. 1998. Effect of angiotensinconverting-enzyme (ACE) inhibitor trandolapril on human diabetic neuropathy: randomised double-blind controlled trial. Lancet, 352:1978-81.

Malmberg K, Ryden L, Hamsten A, et al. 1996. Effects of insulin treatment on cause-specific one-year mortality and morbidity in diabetic patients with acute myocardial infarction. DIGAMI Study Group. Diabetes Insulin-Glucose in Acute Myocardial Infarction. Eur Heart J, $17: 1337-44$

Mancia G, De Cesaris R, Fogari R, et al. 1992. Evaluation of the antihypertensive effect of once-a-day trandolapril by 24-hour ambulatory blood pressure monitoring. The Italian Trandolapril Study Group. Am J Cardiol, 70:60D-66D.

Meyer BH, Muller FO, Badenhorst PN, et al. 1995. Multiple doses of trandolapril do not affect warfarin pharmacodynamics. $S$ Afr Med J, 85:768-70.

Miettinen H, Haffner SM, Lehto S, et al. 1996. Proteinuria predicts stroke and other atherosclerotic vascular disease events in nondiabetic and non-insulin-dependent diabetic subjects. Stroke, 27:2033-9.

New JP, Bilous RW, Walker M. 2000. Insulin sensitivity in hypertensive Type 2 diabetic patients after 1 and 19 days" treatment with trandolapril. Diabet Med, 17:134-40.

Omboni S, Ravogli A, Villani A, et al. 1995. Permanent blood pressure control over the $24 \mathrm{~h}$ by trandolapril. Am J Hypertens, 8:71S-74S.

Palardy M, Ducharme A. 2005. Inhibition of the renin-angiotensin system and prevention of atrial fibrillation in heart failure. Heart Drug, 5:214-9.

Pedersen OD, Abildstrom SZ, Ottesen MM, et al. 2006. Increased risk of sudden and non-sudden cardiovascular death in patients with atrial fibrillation/flutter following acute myocardial infarction. Eur Heart $J$, 27:290-5.

Pedersen OD, Bagger H, Kober L, et al. 1999. Trandolapril reduces the incidence of atrial fibrillation after acute myocardial infarction in patients with left ventricular dysfunction. Circulation, 100:376-80.

Pepine CJ, Handberg EM, Cooper-Dehoff RM, et al. 2003. A calcium antagonist vs a non-calcium antagonist hypertension treatment strategy for patients with coronary artery disease. The International VerapamilTrandolapril Study (INVEST): a randomized controlled trial. JAMA, 290:2805-16.

Petrie JR, Morris AD, Ueda S, et al. 2000. Trandolapril does not improve insulin sensitivity in patients with hypertension and type 2 diabetes: a double-blind, placebo-controlled crossover trial. J Clin Endocrinol Metab, 85:1882-9.

Pitt B. 2004. ACE inhibitors for patients with vascular disease without left ventricular dysfunction - may they rest in PEACE? $N$ Engl $J$ Med, $351: 2115-7$.

PROCOPA. 2002. Dissociation between blood pressure reduction and fall in proteinuria in primary renal disease: a randomized double-blind trial. J Hypertens, 20:729-37. 
Ravid M, Brosh D, Ravid-Safran D, et al. 1998. Main risk factors for nephropathy in type 2 diabetes mellitus are plasma cholesterol levels, mean blood pressure, and hyperglycemia. Arch Intern Med, 158:998-1004.

Remuzzi A, Puntorieri S, Battaglia C, et al. 1990. Angiotensin converting enzyme inhibition ameliorates glomerular filtration of macromolecules and water and lessens glomerular injury in the rat. J Clin Invest, 85:541-9.

Reneland R, Alvarez E, Andersson PE, et al. 2000. Induction of insulin resistance by beta-blockade but not ACE-inhibition: long-term treatment with atenolol or trandolapril. J Hum Hypertens, 14:175-80.

Ruggenenti P, Fassi A, Ilieva AP, et al. 2004. Preventing microalbuminuria in type 2 diabetes. $N$ Engl J Med, 351:1941-51.

Sarnak MJ, Levey AS, Schoolwerth AC, et al. 2003. Kidney disease as a risk factor for development of cardiovascular disease: a statement from the American Heart Association Councils on Kidney in Cardiovascular Disease, High Blood Pressure Research, Clinical Cardiology, and Epidemiology and Prevention. Circulation, 108:2154-69.

Song JC, White CM. 2002. Clinical pharmacokinetics and selective pharmacodynamics of new angiotensin converting enzyme inhibitors: an update. Clin Pharmacokinet, 41:207-24.

Stoschitzky K. 1999. Trandolapril and human diabetic neuropathy. Lancet, 353:926-7.

Swedberg K, Cleland J, Dargie H, et al. 2005. Guidelines for the diagnosis and treatment of chronic heart failure: executive summary (update 2005): The Task Force for the Diagnosis and Treatment of Chronic Heart Failure of the European Society of Cardiology. Eur Heart J, 26:1115-40.
TRACE. 1994. The TRAndolapril Cardiac Evaluation (TRACE) study: rationale, design, and baseline characteristics of the screened population. The Trace Study Group. Am J Cardiol, 73:44C-50C.

Tytus RH, Burgess ED, Assouline L, et al. 2007. A 26-week, prospective, open-label, uncontrolled, multicenter study to evaluate the effect of an escalating-dose regimen of trandolapril on change in blood pressure in treatment-naive and concurrently treated adult hypertensive subjects (TRAIL). Clin Ther, 29:305-15.

Van Der Ent M, Remme WJ, De Leeuw PW, et al. 1998. Renal hemodynamic effects in patients with moderate to severe heart failure during chronic treatment with trandolapril. Cardiovasc Drugs Ther, 12:395-403.

Wiseman LR, McTavish D. 1994. Trandolapril. A review of its pharmacodynamic and pharmacokinetic properties, and therapeutic use in essential hypertension. Drugs, 48:71-90.

Yusuf S, Sleight P, Pogue J, et al. 2000. Effects of an angiotensinconverting-enzyme inhibitor, ramipril, on cardiovascular events in high-risk patients. The Heart Outcomes Prevention Evaluation Study Investigators. N Engl J Med, 342:145-53.

Zuanetti G, Latini R, Maggioni AP, et al. 1993. Influence of diabetes on mortality in acute myocardial infarction: data from the GISSI-2 study. J Am Coll Cardiol, 22:1788-94. 